DOI: 10.12731/2070-7568-2018-2-40-56

УДК 65.011.46

\title{
МЕТОДИЧЕСКИЕ ПОДХОДЫ К ОЦЕНКЕ ВОЕННО-ЭКОНОМИЧЕСКОГО ЭФФЕКТА В РЕЗУЛЬТАТЕ ВНЕДРЕНИЯ ТЕХНИЧЕСКИХ ИННОВАЦИЙ В СИСТЕМЕ МАТЕРИАЛЬНОГО ОБЕСПЕЧЕНИЯ ВОЙСК (СИЛ)
}

\section{Болдырев О.А., Козин М.Н.}

Задача обеспечения военной безопасности Российской Федеращии в ситуачии интенсивного геополитического давления и технологического превосходства государств, проводящих недружественную политику по отношению к нашей стране, ведет к необходимости технического переоснащения Вооруженных Сил Российской Федерачии на основе инновационных технологий. Однако пока не разработаны методики оченки военно-экономического эффекта от применения технических инноваций в войсках, что может ухудиить качество принимаемых решений относительно цчелесообразности внедрения этих инноващий.

Цель: разработка методики оценки военно-экономического эффекта от применения технических инноваций в системе материального обеспечения Вооруженных Сил Российской Федеращии.

Методы: общенаучные методы анализа и синтеза, метод экономико-математического моделирования.

Результаты: выявлены факторы военно-экономического эффекта от применения технических инновачий в сфере материального обеспечения войск (сил) и построена методика его оченки.

Ключевые слова: технические инновации; материально-техническое обеспечение; военно-экономический эффект.

\section{METHODIC APPROACHES TOWARDS EVALUATION OF ECONOMIC AND MILITARY EFFECT PRODUCED BY IMPLEMENTATION OF TECHNICAL INNOVATIONS IN THE FIELD OF MILITARY LOGISTICS}

\section{Boldyrev O.A., Kozin M.N.}

The problem of guaranteeing military security of Russian Federation in the situation of geopolitical pressure and technological domina- 
tion of the states that carry out unfriendly policy towards our country leads to the necessity to introduce technical innovations in the Armed Forces of Russian Federation. However methods of evaluation of military and economic effect produced by technical innovations in the army have not been proposed which may be a reason of the lower quality of decision making in the field of introduction of these technologies in the Armed Forces of Russian Federation.

Goal of the paper: working out a method of evaluation of military and economic effect produced by technical innovations in the system of material supply of the Armed Forces of Russian Federation.

Methods: analysis, synthesis, method of economic and mathematical modelling.

Results: factors of military and economic effect of use of technical innovations in the field of material supply to the army were identified and a method of evaluation of this effect was proposed.

Keywords: technical innovations; logistics and procurement; military and economic effect.

\section{Введение}

Внедрению инноваций в военной сфере сейчас уделяется чрезвычайно большое внимание, особенно в нашей стране. Это связано с необходимостью обеспечения военной безопасности государства в условиях резкого роста геополитического давления, количественного военного превосходства со стороны государств, проводящих недружественную политику оп отношению к России, и ограниченных финансовых, экономических и демографических ресурсов нашей страны (что связано с непродуманной хозяйственной политикой в первое постсоветское десятилетие, деиндустриализацией экономики, ростом зависимости от зарубежных финансовых и технологических ресурсов, падением рождаемости, оттоком населения за рубеж - прежде всего, наиболее продуктивной части, и замещения оттока лицами с более низким уровнем человеческого капитала и более низким уровнем лояльности - речь идет о трудовых мигрантах). В этой ситуации только внедрение инноваций позволит России 
сохранить военный паритет и даст возможность причинить противнику неприемлемый ущерб.

При этом внедрение инноваций должно охватывать не отдельные элементы военной организации (отдельные войска (силы), отдельные направления функционирования, отдельные регионы и т. д.), а всю военную организацию в целом. В противном случае между элементами военной организации возникнет диспаритет, на практике проявляющийся в «узких местах», когда потенциал одного элемента не будет соответствовать потенциалу другого. Как следствие, при принятии военных решений придется ориентироваться на элемент с наиболее низким потенциалом, что обесценит более высокий потенциал других элементов.

В настоящее время наиболее активно обсуждается внедрения инноваций, связанных непосредственно с вооружением и военной техникой для ведения боевых действий (гиперзвуковые ракеты «Циркон», авиационный комплекс «Кинжал» и т. д.), тогда как вопросы инновационного развития других сфер деятельности военной организации Российской Федерации достаточного освещения не получили. В данной статье мы рассмотрим проблемы использования технических инноваций в сфере материально-технического обеспечения (МТО) войск (сил).

Применение инноваций в такой специфической сфере, как военная, должно опираться на научно-методический аппарат обоснования целесообразности этих инноваций $[1,2,4]$. Цель предлагаемой статьи состоит в разработке такого элемента этого научно-методического аппарата, как методика расчета военноэкономического эффекта от использования инноваций в сфере МТО войск (сил).

Проблемам оценки эффекта от тех или иных мероприятий (в том числе и от внедрения организационных $[5,8,9,12,13,14,15]$ и технологических инноваций $[3,6,16])$ посвящено значительное количество публикаций, что связано с тем, что управленческие решения о целесообразности проведения этих мероприятий принимаются на основе ожидаемого от них эффекта. 
Специалисты выделяют два подхода к оценке эффекта - однокритериальный и многокритериальный [7, 10].

1. Однокритериальный подход предполагает оценку только одного из аспектов результата, достигнутого благодаря проведению мероприятий. Удобство этого подхода состоит в том, что полученный показатель эффекта, как правило, обладает прозрачным управленческим смыслом (снижение затрат, сокращение времени на выполнение операций, прирост надежности и т. д.). Недостаток состоит в том, что проведенное мероприятие, став причиной улучшения одних характеристик системы, может привести к ухудшению других характеристик системы, причем это ухудшение может быть настолько значимым, что полностью нивелирует положительный эффект (оцениваемый при помощи однокритериального показателя). Однако выявить факт этого ухудшения при помощи однокритериального показателя невозможно, что искажает принимаемые управленческие решения [7, 10].

2. Многокритериальный подход, включает в себя расчёт несколько частных (однокритериальных) показателей эффекта, которые затем, при помощи специально заданной процедуры свертки, используются для определения обобщенного показателя эффекта $[7,10]$. Преимущество этого подхода состоит в том, что он принимает во внимание различные аспекты ожидаемого эффекта, тогда как недостаток заключается в том, что сам многокритериальный показатель лишен явного управленческого смысла, а сама процедура его расчета (свертка) может быть задана неверно.

В существующих исследованиях [13] было показано, что в деятельности военной организации государства выделяются два аспекта: военный (способность обеспечивать военную безопасность государства) и экономический (величина затрат на формирование и поддержание функционирования военной организации). Оба эти аспекта необходимо учитывать при принятии управленческих решений в военной сфере, при этом ни в коем случае нельзя 
отдавать предпочтение какому-либо одному из них (в противном случае либо затраты на военную организацию станут неприемлемыми для национальной экономики, либо военная организация столкнется с невозможностью эффективно выполнять свои функции из-за недостатка финансирования; иными словами, одинаково неприемлемыми при принятии решений в военной сфере являются как избыточно милитаристский, так и прямолинейный бухгалтерский подходы). Следовательно, при оценке эффекта от применения инновации в сфере МТО войск (сил) следует использовать интегральный показатель военно-экономического эффекта, который будет рассчитываться путем свертки частных показателей военного и экономического эффектов.

В существующей литературе по вопросам инновационной деятельности в военной сфере $[4,15,16,17,18]$ было показано, что внедрение инноваций в военной организации государства представляет собой инвестиционный проект, и поэтому экономический эффект инноваций следует рассчитывать, как экономический эффект соответствующего инвестиционного проекта. К сожалению, мнения специалистов относительно того, какой именно показатель из большого числа используемых в практике гражданских предприятий следует применять для оценки эффективности инноваций в военной сфере расходятся

Что касается военного эффекта, то здесь также нет единства мнений относительно того, как именно его следует измерять. Это связано с тем, что разные виды инноваций ведут к разным типам экономического эффекта. В силу этого общих методик оценки военного эффекта от применения инноваций нет, а авторы, писавшие на эту тему, оценивали военный эффект от конкретных инноваций путем измерения параметров, связанных именно с этими инновациями. Общей методики оценки военного эффекта от инноваций пока предложено не было.

С учетом выполненного нами обзора существующего состояния исследований мы можем констатировать, что пока нет определенности ни относительно подхода к оценке экономического эффекта от инноваций, ни относительно военного эффекта. 


\section{Методы}

В статье использованы общенаучные методы анализа и синтеза, а также метод экономико-математического моделирования.

\section{Результаты}

Оценку эффективности инвестиционного проекта можно проводить на основе абсолютных и относительных показателей. Наиболее распространенным относительным показателем является чистый дисконтированный доход (ЧДД), рассчитываемый по формуле

$$
\text { ЧДД }=\sum_{i=1}^{n} \frac{C F_{i}}{(1+d)} \text {, }
$$

где

$n$ - число лет, для которого рассчитывается величина ЧДД;

$C F_{i}$ - денежный поток в течение $i$-го периода;

$d$ - ставка дисконтирования.

Применительно к особенностям функционирования военной организации государства источником положительного денежного потока является снижение затрат на функционирование системы МТО, достигнутое благодаря внедрению инноваций. Отрицательный денежный поток порождается затратами на внедрение инновации.

Удобство показателя ЧДД состоит в том, что он позволяет получить оценку экономического эффекта в денежном выражении. Однако важный недостаток заключается в том, что он не обеспечивает соизмеримость экономического эффекта. Эта несоизмеримость проявляется в двух отношениях:

1) сложно сопоставлять инновационные проекты, имеющие близкие значения ЧДД, но разные величины затрат на их проведение;

2) показатель ЧДД измеряется в денежных единицах, что делает его несопоставимым с показателем военного эффекта.

Наиболее часто используемым относительным показателем экономического эффекта инвестиционного проекта является индекс доходности ИД, который рассчитывается по формуле 


$$
\text { ИД }=\frac{\text { И ч ЧДД }}{\text { ЧДД }}
$$

где И - инвестиции на реализацию инновационного проекта.

Легко убедиться, что индекс доходности не обладает недостатками, присущими показателю чистого дисконтированного дохода, и обеспечивает соизмеримость как экономического эффекта различных инновационных проектов, так и экономического и военного эффектов. Кроме того, индекс доходности обладает прозрачным экономическим и управленческим смыслом и может служить удобной основой для принятия решений. По этой причине для оценки экономического эффекта от использования инноваций в сфере МТО мы рекомендуем именно этот показатель.

Что касается военного эффекта, то мы предлагаем измерять его при помощи двух параметров: роста производительности и роста надежности (далее для краткости прости производительности и надежности). Производительность $K$ показывает, насколько улучшились технические характеристики системы МТО (или одной из ее подсистем) благодаря внедрению инновации:

где

$$
K=\prod_{j=1}^{m}\left(\frac{\mathrm{P}_{j 1}}{\mathrm{P}_{j 0}}\right)^{a_{j} b_{j}},
$$

$m$ - число значимых характеристик системы (подсистемы) MТО, на изменение значений которых направлено внедрение инноваций;

$P_{j 1}$ - значение $j$-й характеристики после внедрения инновации;

$P_{j 0}$ - значение $j$-й характеристики до внедрения инновации;

$a_{j}-$ вес $j$-й характеристики;

$b_{j}$ - параметр, описывающий желаемое направление изменения $j$-й характеристики; $b_{j}=1$, если необходимо обеспечить выполнение условия $P_{j 1}>P_{j 0}$, и $b_{j}=-1$ в противном случае [11].

Показатель надежности $H$ рассчитывается по формуле

где

$$
H=\frac{R_{1}}{R_{0}},
$$

$R_{1}$ - уровень устойчивости системы МТО к негативным воздействиям до внедрения инновации; 
$R_{0}$ - уровень устойчивости системы МТО к негативным воздействиям после внедрения инновации.

Надежность можно было бы включить в качестве одного из множителей в формулу (2), однако мы полагаем, что значимость надежности как характеристики системы МТО военной организации исключительно высока, что обуславливает необходимость ее рассмотрения в качестве самостоятельного параметра.

Oсобое значение надежность приобретает сейчас. В настоящее время, когда Вооруженные Силы Российской Федерации (ВС РФ) вынуждены противодействовать возможным военным угрозам на значительном удалении от государственных границ (сирийская кампания), устойчивость логистической системы играет ключевую роль в обеспечении способности военной организации государства эффективно выполнять свои функции.

Кроме того, внедряемые в настоящее время инновации носят ярко выраженный цифровой характер, то есть основаны на удаленном доступе и активном использовании коммуникационных сетей. Эти инновации значительно повышают эффективность функционирования логистических систем, но при этом ведут к росту их уязвимости перед киберугрозами. Поэтому, принимая решение о внедрении технических инноваций, необходимо тщательно оценить, насколько эти инновации снизят устойчивость системы МТО по отношению к враждебным воздействиям.

Итоговое значение военного эффекта Mil может быть определено по формуле

$$
\text { Mil }=\sqrt{K^{A} H^{B}},
$$

где $A$ и $B$ - значения весов производительности и надежности соответственно.

Таким образом, военный эффект сам по себе является сложным показателем, основанным на свертке показателей производительности и надежности (при этом показатель производительности также представляет собой свертку определенного набора частных показателей).

На сегодняшний день существует значительное количество процедур свертки для расчета интегральных показателей эффекта. Од- 
нако, исходя из целей нашего исследования, мы считаем оптимальной процедуру расчета среднего взвешенного геометрического по следующим причинам:

- мы работаем с относительными показателями, и поэтому, в соответствии со сложившейся в теории принятия решений практикой, интегральный показатель должен рассчитываться путем перемножения частных показателей;

- отдельные индивидуальные характеристики системы МТО имеют разное значение с точки зрения их важности для обеспечения надлежащего функционирования этой системы, что можно учесть при помощи введения весов.

Исходя из аналогичных умозаключений, мы предлагаем рассчитывать интегральный военно-экономический эффект от внедрения инноваций ВЭИ по формуле

$$
\text { ВЭИ }=\sqrt{И Д^{D} \mathrm{Mil}^{F}}
$$

где $D$ и $F$ - веса индекса доходности и военного эффекта соответственно (напомним, что индекс доходности в соответствии с нашими предложениями выступает в качестве меры экономического эффекта).

Принятие решения о внедрении инновации должно происходить на основе выполнения следующего условия:

где

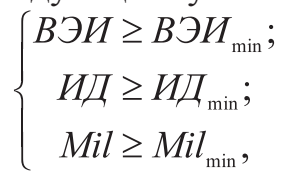

ВЭИ ${ }_{\text {min }}$ - минимальное допустимое значение военно-экономического эффекта, устанавливаемое органами военного управления. Отметим, что, исходя из опыта аналогичных по своей методологической основе алгоритмов, мы могли бы требовать выполнения условия ВЭИ > 1, однако, по нашему мнению, такой подход является неправильным. Недостаточно, чтобы военно-экономический эффект был положительным, необходимо, чтобы он был не меньше некоего заранее установленного значения (в частности, для того, чтобы обеспечить страховку от рисков недостаточно эффективного внедрения); 
$И_{\text {min }}$ - минимальное допустимое значение экономического эффекта (индекса доходности);

$\mathrm{Mil}_{\min }$ - минимальное допустимое значение военного эффекта.

В том случае, если в одной и той же подсистеме МТО войск (сил) может быть реализовано несколько взаимоисключающих инновационных проектов, выбор оптимального из них необходимо осуществлять на основе условия

$$
\left\{\begin{array}{l}
\text { ВИ } \rightarrow \max \\
И Д \geq И Д_{\min } \\
M i l \geq M i l_{\min }
\end{array}\right.
$$

\section{Обсуждение}

Предложенная методика оценки военно-экономического эффекта носит достаточно общий характер. По этой причине мы специально не разрабатывали перечень частных показателей военного эффекта, поскольку они будут различаться для разных сфер применения инноваций в области МТО. Основные отличия будут наблюдаться в составе частных показателей производительности, а также в точном перечне источников положительных денежных потоков при расчете индекса доходности. Кроме того, могут различаться значения весов (формулы (2-4)) - не будет ошибкой предположить, что, чем ближе будет область применения той или иной инновации к ситуации боевых действий, тем выше при расчете величины военно-экономического эффекта (формула (4)) будет значимость военной составляющей и тем ниже - значимость экономической компоненты.

Таким образом, предложенная нами методика может выступать в качестве методологической основы для разработки конкретных алгоритмов оценки военно-экономического эффекта в различных сферах МТО ВС РФ. Ее адаптация к конкретным подсистема МТО ВС РФ будет происходить путем уточнения перечня источников положительного денежного потока, конкретизации перечня показателей производительности, а также определения значения весов (с учетом специфики соответствующей подсистемы МТО ВС РФ). 


\section{Выводы}

Наши выводы заключаются в следующем:

- в качестве наиболее удобной меры экономического эффекта от внедрения инноваций в сфере МТО ВС РФ выступает индекс доходности. Это связано с тем, что он является относительным показателем, благодаря чему достигается соизмеримость экономического эффекта с военным, а также соизмеримость экономического эффекта от разных видов инноваций и от разных вариантов их внедрения;

- при оценке военного эффекта следует учитывать производительность системы МТО ВС РФ и ее надежность. Выделение надежности в качестве самостоятельного элемента военного эффекта связано с важностью надежности системы МТО ВС РФ для обеспечения полноценного функционирования национальной военной организации;

- предложенная нами методика оценки военно-экономического эффекта от внедрения инноваций в сфере МТО ВС РФ носит общий характер. Ее адаптация к задачам оценки военно-экономического эффекта от внедрения конкретных инноваций в конкретных подсистемах МТО ВС РФ будет происходить путем уточнения перечня источников положительного денежного потока (т. е. того, за счет каких факторов будет достигать снижение затрат на выполнение системой МТО ВС РФ своих функций), перечня показателей производительности и значений весов различных показателей.

\section{Список литературы}

1. Богатырева С.В., Титов А.Б., Куприянова М.Ю. Экономическая эффективность как основа формирования управленческих решений // Экономика и менеджмент систем управления. 2016. Т. 20. № 2.1. С. 116-122.

2. Вертакова Ю.В., Козьева И.А., Кузьбожев Э.Н. Управленческие решения: разработка и выбор. М.: КНОРУС, 2005. 352 с.

3. Демидов Б.А., Луханин М.И., Величко А.Ф., Науменко М.В. Системная методология планирования развития, предпроектных исследо- 
ваний и внешнего проектирования вооружения и военной техники. К.: Стилос, 2011. 464 с.

4. Дрещинский В.А., Коновалов В.Б. Стимулирование научно-технической и инновационной деятельности в интересах материальнотехнического обеспечения вооруженных сил // Инновации. 2017. № 5 (223). С. 68-74.

5. Евсеев Д.Г., Щербаков К.Г. Сервисное обслуживание ТПС с управлением жизненным циклом // Мир транспорта. 2014. Т. 12. № 3. C. $134-139$.

6. Жуков Г.П., Викулов С.Ф. Военно-экономический анализ и исследование операций. М.: Воениздат, 1987. 440 с.

7. Котляров И.Д. Алгоритм принятия решения об использовании аутсорсинга в нефтегазовой отрасли // Проблемы экономики и управления нефтегазовым комплексом. 2010. № 11. С. 33-38.

8. Котляров И.Д. Алгоритм отбора аутсорсеров по критерию способности обеспечить целевые значения показателей, описывающих передаваемый процесс // Проблемы экономики и управления нефтегазовым комплексом. 2012. № 10. С. 50-54.

9. Котляров И.Д. Принятие решение об использовании аутсорсинга с учетом фактора риска // Вісник Хмельницького національного університету. Економічні науки. 2015. Т. 3. № 3. С. 106-110.

10.Котляров И.Д. Проблемы оценки эффективности аутсорсинга // Вестник Института экономики Российской академии наук. 2017. № 6. С. 87-99.

11. Котляров И.Д., Сычева О.С. Оценка конкурентоспособности предприятия сферы услуг: модель плавающих весов // Практический маркетинг. 2010. № 11. С. 11-15.

12. Красовитов Р.А., Курбанов А.Х. Научно-методическое сопровождение внедрения концепции «Индустрии 4.0» в сфере вещевого обеспечения военных потребителей // Экономика и предпринимательство. 2017. № 10-2 (87-2). С. 761-767.

13. Курбанов А.X. Аутсорсинг: теория, методология, специфика применения в военной организации. СПб.: Копи-Р Групп, 2011. 277 с. 14. Курбанов А.Х., Курбанов Т.Х., Плотников В.А. Модель военноэкономического обоснования стационарной системы хранения ма- 
териально-технических средств тыла для ВС РФ нового облика // Вооружение и экономика. 2011. № 1. С. 139-148.

15. Курбанов А.Х., Лабазанов С.Г., Плотников В.А. Организационноэкономические инновации в деятельности силовых структур государства // Научно-технические ведомости Санкт-Петербургского государственного политехнического университета. Экономические науки. 2006. № 48-2. С. 137-142.

16. Курбанов Т.X. «Склад будущего» как основной элемент эффективной системы материально-технического обеспечения военной организации государства // Вопросы оборонной техники. Серия 16: Технические средства противодействия терроризму. 2017. № 1-2 (103-104). С. 137-143.

17. Курбанов Т.Х. Методика военно-экономического обоснования перемещения запасов материальных средств на производственно-логистические комплексы военной организации государства // Экономика и предпринимательство. 2017. № 12-2 (89-2). С. 766-772.

18. Паршина Н.Н., Агеев А.О., Сахаров Е.В. Повышение эффективности управления материально-техническим обеспечением ВС РФ на основе рациональной организации информационного обмена органов военного управления МТО и федеральных органов исполнительной власти // Наука и военная безопасность. 2017. №2 (9). С. 69-73.

\section{References}

1. Bogatyreva S.V., Titov A.B., Kupriyanova M.Yu. Ekonomicheskaya effektivnost kak osnova prinyatiya resheniy [Economic effectiveness as a basis of decision making]. Ekonomika $i$ menedzhment system upravleniya [Economy and management of regulation systems], 2016, V. 20, no 2.1, pp. 116-122.

2. Vertakova Yu.V., Koz'yeva I.A., Kuzbozhev E.N. Upravlencheskie resheniya: razrabotka $i$ vybor [Management decisions: working out and choice]. Moscow: KNORUS, 2005. 352 p.

3. Demidov B.A., Lukhanin B.A., Velichko A.F., Naumenko M. V. Sistemnaya metodologiya planirovaniya razvitiya, predproektnykh issledovaniy $i$ vneshnego proektirovaniya vooruzheniya i voennoy tekhniki [System 
methodology of planning of development, early project researches and external projects of weapons and military equipment]. Kiev: Stilos, 2011. $464 \mathrm{p}$.

4. Dreshchinski V.A., Konovalov V.B. Stimulirovanie nauchno-technicheskoy $\mathrm{i}$ innovatsionnoy deyatel'nosti v interesakh material'no tekhnicheskogo obespecheniya vooruzhennykh sil [Stimulating of research and development and innovation activity for the military logistics]. Innovatsii [Innovations], 2017, no 5, pp. 68-74.

5. Evseev D.G., Shcherbakov K.G. Servisnoe obsluzhivanie TPS s upravleniem zhiznennym tsiklom [Technical service of locomotives based on life cycle management]. Mir transporta [World of transport], 2014, V. 12, no 3, pp. 134-139.

6. Zhukov G.P., Vikulov S.F. Voenno-ekonomicheskiy analiz i issledovanie operatsiy [Military economic analysis and operation research]. Moscow: Voenizdat, 1987. $440 \mathrm{p}$.

7. Kotliarov I.D. Algoritm prinyatiya resheniya ob ispol'zovanii autsorsinga v neftegazovoy otrasli [An algorithm of decision making for use of outsourcing in the oil and gas industry]. Problemy ekonomiki i upravleniya neftegazovym kompleksom [Problems of economics and management in the oil and gas complex], 2010, no 11, pp. 33-38.

8. Kotliarov I.D. Algoritm otbora autsorserov po kriteriyu sposobnosti obespechit tselevye znacheniya pokazateley, opisyvayushchikh peredavaemyy protsess [An algorithm of selection of outsources based on the criterion of their ability to ensure target values of indicators that describe the outsourced process]. Problemy ekonomiki i upravleniya neftegazovym kompleksom [Problems of economics and management in the oil and gas complex], 2012, no 10, pp. 50-54.

9. Kotliarov I.D. Prinyatie resheniya ob ispol'zovanii autsorsinga s uchetom faktora riska [Decision-making for the use of outsourcing taking into account the factor of risk]. Visnyk Khmel'nitskogo natsional'nogo universytetu. Ekonomichni nauky [Journal of Hmelnitsky national university. Economic sciences], 2015, V. 3, no 3, pp. 106-110.

10. Kotliarov I.D. Problemy otsenki effektivnosti autsorsinga [Problems of evaluation of effectiveness of outsourcing]. Vestnik Instituta ekonomi- 
ki Rossiyskoy akedemii nauk [Journal of the Institute of Economics of Russian Academy of Sciences], 2017, no 6, pp. 87-99.

11. Kotliarov I.D., Sucheva O.S. Otsenka konkurentosposobnosti predpriyatiya sfery uslug: model plavayushchikh vesov [Evaluation of competitiveness of service companies: model of floating weights]. Prakticheskiy marketing [Practical marketing], 2010, no 11, pp. 11-15.

12.Krasovitov R.A., Kurbanov A.Kh. Nauchno-metodicheskoe soproozhdenie vnedreniya kontseptsii "Industrii 4.0" v sfere veshchevogo odespecheniya voennykh potrebiteley [Scientific and methodological support of the implementation of the concept of the "Industry 4.0" in the field of material supply to military customers]. Economika $i$ predprinimatel'stvo [Economics and entrepreneurship], 2017, no 102, pp. 761-767.

13. Kurbanov A.Kh. Autsorsing: teoriya, metodologiya, spetsifika primeneniya $v$ voennoy organizatsii [Outsourcing: theory, methodology, specificity of implementation in the military organization]. St. Petersburg: Koppi_R Grupp, 2011. 277 p.

14.Kurbanov A.Kh., Labazanov S.G., Plotnikov V.A. Organizatsionno-ekonomicheskie innovatsii v deyatelnosti silovykh struktur gosudarstva [Organizational and economic innovations in the activity of the enforcement structures of the state]. Nauchno-tekhnicheskie vedomosti Sankt-Peterburgskogo gosudarstvennogo politekhnicheskogo universiteta. Ekonomicheskie nauki [Scientific and technical journal of St. Petersburg state polytechnic university. Economic sciences], 2006, no 48-2, pp. 137-142.

15. Kurbanov A.Kh., Kurbanov T.Kh., Plotnikov V.A. Model voenno-ekonomicheskogo obosnovaniya statsionarnoy sistemy khraneniya materialno-tekhnicheskikh sredstv tyla dlya VS RF novogo oblika [A model of military and economic substantiation of a stationary system of stocks for technical equipment of military logistics for the new type of the Armed Forces of Russian Federation]. Vooruzhenie $i$ ekonomika [Weapons and economics], 2011, no 1, pp. 139-148.

16. Kurbanov T.Kh. "Sklad budushchego" kak osnovnoy element effektivnoy sistemy materialno-tekhnicheskogo obespecheniya voennoy organizat- 
sii gosudarstva ["Stock of the future" as a main element of the effective system of material and technical supply to the military organization of the state]. Voprosy oboronnoy tekhniki. Seriya 16: Tekhnicheskie sredstva protivodeystviya terrorizmu [Problems of defense technologies. Series 16: Technical tools of counter-terrorism activities], 2017, no 1-2 (103-104), pp. 137-143.

17. Kurbanov T.Kh. Metodika voenno-ekonomicheskogo obosnovaniya peremeshcheniya zapasov materialnykh sredstv na proizvodstvenno-logisticheskie kompleksy voennoy organizatsii gosudarstva [A method of military and economic substantiation of the transfer of material reserves to production and logistics complexes of the military organization of the state]. Ekonomika i predprinimatelstvo [Economics and entrepreneurship], 2017, no 12-2 (89-2), pp. 766-772.

18. Parshina N.N., Ageev A.O., Sakharov E.V. Povyshenie effektivnosti upravleniya materialno-tekhnicheskim obespecheniem VS RF na osnove ratsionalnoy organizatsii informatsionnogo obmena organov voennogo upravleniya MTO i federalnykh organov ispolnitelnoy vlasti [Increase of effectiveness of the management of military logistics of the Armed Forces of Russian Federation on the basis of rational organization of information exchange of the military logistcs administration and federal executive organizations], Nauka $i$ voennaya bezopasnost [Science and military security], 2017, no 2 (9), pp. 69-73.

\section{ДАННЫЕ ОБ АВТОРАХ}

Болдырев Олег Алексеевич, преподаватель кафедры материального обеспечения

Военная академия материально-технического обеспечения имени генерала армии А. В. Хрулёва

наб. Макарова, 8, г. Санкт-Петербург, 199034, Российская Федерация

oboldyreff1976@gmail.com

Козин Михаил Николаевич, д.э.н., профессор, ведущий научный сотрудник 
56 Siberian Journal of Economics and Management, Vol. 7, No 2, 2018

Научно-исследовательский институт Федеральной службы исполнения наказаний Российской Федерации

ул. Житная, 14, г. Москва, 119991, Российская Федерация

\section{DATA ABOUT THE AUTHORS}

Boldyrev Oleg Alekseyevich, Lecturer, Chair of Material Supply

General of Army Andrey V. Khrulev Military Academy of Procurement and Logistics

8, nab. Makarova, St. Petersburg, 199034, Russian Federation oboldyreff1976@gmail.com

Kozin Mikhail Nikolayevich, D.Sc. (Economics), Head Researcher Scientific Research Institute Federal Penitentiary Service of Russian Federation

14, Zhitnaya Str., Moscow, 119991, Russian Federation 